\title{
Desorption capacity of raw energy bars with fruits of Zizyphus jujuba Mill. - Bulgaria
}

\author{
Albena Durakova ${ }^{1, *}$, Adelina Vasileva $^{2}$, Tzvetana Gogova ${ }^{3}$, Milena Temelkova $^{4}$ and \\ Rumyana Krasteva ${ }^{5}$ \\ $1^{*}$ Department of Process Engineering, University of Food Technologies - Plovdiv, 26 Maritza Blvd. \\ BG-4002 Plovdiv, Bulgaria \\ ${ }^{2}$ Department of Mechanical and Instrument Engineering, Technical University - Sofia, Plovdiv \\ Branch, 25 Tsanko Duistabanov Str., Plovdiv 4000, Bulgaria \\ ${ }^{3}$ Department of Technology of Grain, Fodder, Bread and Confectionery Products, University of Food \\ Technologies - Plovdiv, 26 Maritza Blvd. BG-4002 Plovdiv, Bulgaria \\ ${ }^{4}$ Language Training Centre, University of Food Technologies - Plovdiv, 26 Maritza Blvd. BG-4002 \\ Plovdiv, Bulgaria \\ ${ }^{5}$ Centre of Physical Education and Sport, University of Food Technologies - Plovdiv, 26 Maritza \\ Blvd. BG-4002 Plovdiv, Bulgaria
}

\begin{abstract}
The current study presents a mixture for raw energy bars of fresh fruits of the exotic fruit Zizyphus jujuba Mill. with origin - Bulgaria. The physico-chemical indices of the ready mixture are analyzed. A high content of carbohydrates $-24.45 \%$ and of nourishing fiber $-22.08 \%$ is reported. The desorption capacity of the exotic mixture is examined for temperatures of $10^{\circ} \mathrm{C}, 25^{\circ}$ and $40^{\circ} \mathrm{C}$ in eight watery activities from $11 \%$ to $85 \%$. The analysis shows that the equilibrium moisture lowers with the raise of temperature in constant watery activities. The desorption isotherms are of type III according to the classification of Brunauer et al. The modified model of Halsey is recommended for the isotherms description according to the estimation criteria distribution, and the model of Oswin as a second modified model. The values of the monolayer moisture content in $\mathrm{a}_{\mathrm{w}}<0.5$ for temperatures $10^{\circ} \mathrm{C}-5.46 \%$ dry basis (d.b.), $25^{\circ} \mathrm{C}-5.72 \%$ d.b. and $40^{\circ} \mathrm{C}-4.05 \%$ d.b. are calculated Brunauer-Emett-Teller model.
\end{abstract}

Keywords: Zizyphus jujuba Mill, sorption isotherms, raw bars.

\section{Introduction}

The modelling of the mass transfer processes - sorption characteristics, provides the opportunity the regimes and the ways of treatment, preservation and packaging of the nourishing products to be examined [1-3]. The sorptions isotherms allow to be examined the character and the quality of the different types of connected water [4-5]. The monolayer moisture content (MMC), an important sorption characteristic, influencing the products

\footnotetext{
* Corresponding author: aldurakova@abv.bg
} 
microbiological stability, is calculated through the Brunauer-Emmett-Teller (BET) model [6-8]. More and more studies are directed to the prospecting of natural plants with a high content of biologically active components in the last years [9] According to Jinous Asgarpanah and Elaheh Haghighat the Zizyphus jujuba Mill (the Chines fruit of the date plant) is between the five most useful medical plants in the world [10]. The fruits of the Zizyphus jujuba Mill contain a lot of valuable nutrients for the human organism: sugars, proteins, acids and fats. They are extremely rich in cobalt, iodine, iron, high content of vitamin C [11-12]. The fruits are used except for food, as a medical treatment for disorders of the respiratory and the digestive systems. The fruits have the capacity to lower the blood pressure and to regulate the cholesterol. Zizyphus jujuba Mill contains kaempferol and myricetin, flavonoids, characterized with strong antioxidant, cardio protective and anticancer activity. The fruits of Zizyphus jujuba Mill contain the glycoside neomirtilin, which has the capacity to regulate the glucose levels with people suffering from diabetes mellitus. A daily intake of a glass of fresh fruits is recommended, as the researchers think that the levels of the blood sugar will normalize in a week in that way [13-14].

The proper and responsible choice of food can be a real challenge. The discovery of food providing energy, both nourishing and healthy, is one of the main goals of the contemporary person. The raw bars prepared in home conditions are a good alternative for satisfaction the organism's needs from the necessary quality of useful materials.

No details for the desorption capacity of a mixture for raw energy bars of fresh fruits of Zizyphus jujuba Mill. with Bulgarian origin were found in the carefully made literature survey, which gave us grounds for fulfilment of the present study.

\section{Materials and methods}

\subsection{Materials}

The object of the present study is jujube (Zizyphus jujuba Mill.) of Bulgarian origin supplied by an experimental facility in the town of Assenovgrad, Bulgaria.

Oatmeal, flax seeds with mulberry, raw sunflower seeds, dried plums and Rozhkov flour - purchased in Bulgaria by "Internet café-BG" ltd, packed by "Zoya bg Organic Shop".

\subsection{Methods}

Rules for taking of samples and methods of examination - according to Bulgarian State Standard BDS 754:1980/Amendment 4: 2003 [15]

pH - Bulgarian State Standard (BDS) EN ISO 11688:1993 [16];

Dry matter, in weight - BDS EN ISO 12145:2000 [17];

TTA (total titratable acidity) BDS EN ISO 6996:1993 [18];

Fibre - BDS EN ISO 11374:1986 [19];

Fat content, (\%) - Soxhlet method via solvent extraction with petroleum ether. BDS EN ISO 6997:1984 [20];

Carbohydrate - BDS EN ISO 7169:1989 [21];

Protein - Direct Kjeldahl method analysis (determination of nitrogen content/ nitrogen determination method) - Regulation (EC) №152/2009 [22];

Energy value - Regulation 1169:2011, Appendices IVX ; XV [23].

Moisture, $(\%)$ of the products studied - expressed in dry basis 5 standard method via drying of $5 \mathrm{~g}$ of flour at $105^{\circ} \mathrm{C}$ to constant weight, according to AOAC, 1990 [24].

The resulting products dosage is made manually on a scale „Mettler Toledo”. 
The dough mass kneading is done manually.

The examination of desorption capacity of the ready mixture for raw energy bars is made through the static gravimetrical method [25]. For the description of the sorption are used the modified three-parametrical methods of Oswin, Chung-Pfost, Halsey and Henderson. The coefficients (A, B and C) are determined by a program for nonlinear regression "Statistica” (procedure „Nonlinear estimation“). MMC values are calculated using the model of Brunayer-Emmett-Teller with program Excel by the method of the smallest squares [8]. The whole methods is fully described and presented by Durakova et al., [26-28].

\section{Results and discussion}

A mixture for raw energy bars of fresh fruits of Zizyphus jujuba Mill of Bulgarian origin is prepared. The mixture consists of fresh fruits of Zizyphus jujuba Mill - Bulgaria - 41\%, oatmeal $-23 \%$, flax seed with mulberries $-9 \%$, dried plums $-22 \%$, raw sunflower seeds $4 \%$, Rozhkov flour $-1 \%$. The physico-chemical indices of the composed mixture are analyzed and introduced in Table 1.

Table 1. Physico-chemical indices of a mixture of fresh fruits of Zizyphus jujuba mill for raw energy bars of 100 gr ready product.

\begin{tabular}{lcccc}
\hline Name of the index & $\begin{array}{c}\text { Quantity } \\
\text { units }\end{array}$ & Results & $\begin{array}{c}\text { Standard } \\
\text { deviation }\end{array}$ & Conditions \\
\hline Dry quantity, weight & $\%$ & 68.27 & \pm 0.69 & $105 \pm 1{ }^{\circ} \mathrm{C}$ \\
PH & $\%$ & 4.86 & \pm 0.05 & $25 \pm 2{ }^{\circ} \mathrm{C}$ \\
Acidity (titratable) & $\%$ & 0.52 & \pm 0.10 & $25 \pm 2^{\circ} \mathrm{C}$ \\
Fats & $\%$ & 7.96 & \pm 0.33 & $25 \pm 2^{\circ} \mathrm{C}$ \\
Carbohydrates & $\%$ & 24.45 & \pm 0.20 & $25 \pm 2{ }^{\circ} \mathrm{C}$ \\
Proteins & $\%$ & 22.08 & \pm 0.07 & $25 \pm 2^{\circ} \mathrm{C}$ \\
Fibre & $\%$ & \pm 0.53 & $25 \pm 1{ }^{\circ} \mathrm{C}$ \\
Energy value & $\mathrm{Kcal} / \mathrm{KJ}$ & $193.2 / 807.8$ & & \\
\hline
\end{tabular}

The high percentage content in 100 gr product of dry quantity - $68 \%$, carbohydrates $24.45 \%$, nourishing fibre $-22.08 \%$ make impression from the results. The carbohydrates are of high importance for the functioning of the muscle system, the brain and the central nerve system. The nourishing fibre accelerates the food passage through the gastrointestinal tract, cleaning it from toxins and other unfavourable matters. It is considered that the products with high content of fibre have extremely healthy effect [29].

The analyses for the examination of the sorption characteristics of the mixture for raw energy bars are made for three temperatures $-10^{\circ} \mathrm{C}, 25^{\circ} \mathrm{C}$ and $40^{\circ} \mathrm{C}$ in an environment created by eight saturated solutions of salts, sustaining above their surface watery activities $\left(\mathrm{a}_{\mathrm{w}}\right)$ in the range between 0.11 to 0.85 . The initial moisture of the examined product is $42.27 \%$, due to which the moisture migration from the product to the surroundings is interesting, and the examination is hold only for the process of desorption. It is observed that the equilibrium moisture content lowers with the increase of temperature for constant water activity, a behavior relevant to a row of nutrients, studied by many authors [30-31]. As for example for $\mathrm{a}_{\mathrm{w}}=0.431$ the equilibrium moisture content from $40^{\circ} \mathrm{C}$ to $10^{\circ} \mathrm{C}$ has lowered with $3.19 \%$ d.b. 
Table 2. Equilibrium moisture content EMC, \% d.b. of a mixture of fresh fruits of Zizyphus jujuba mill for raw energy bars

\begin{tabular}{lccccccccc}
\hline Sel & & $\mathbf{1 0}^{\circ} \mathbf{C}$ & & \multicolumn{2}{c}{$\mathbf{2 5}^{\circ} \mathbf{C}$} & & $\mathbf{4 0}^{\circ} \mathbf{C}$ \\
& $\mathbf{a}_{\mathbf{w}}$ & $\mathbf{M d}^{* *}$ & $\mathbf{a}_{\mathbf{w}}$ & $\mathbf{M}^{*}$ & $\mathbf{s d}^{* *}$ & $\mathbf{a}_{\mathbf{w}}$ & $\mathbf{M d}^{* *}$ \\
\hline $\mathbf{L i C l}$ & 0.113 & 8.77 & 0.05 & 0.113 & 5.99 & 0.11 & 0.112 & 4.46 & 0.06 \\
$\mathbf{C H 3 C O O K}$ & 0.234 & 9.48 & 0.13 & 0.225 & 6.78 & 0.16 & 0.201 & 4.54 & 0.09 \\
$\mathbf{M g C l}_{\mathbf{2}}$ & 0.335 & 10.28 & 0.28 & 0.328 & 8.02 & 0.14 & 0.316 & 4.85 & 0.12 \\
$\mathbf{K}_{\mathbf{2}} \mathbf{C O}_{3}$ & 0.431 & 10,66 & 0.08 & 0.432 & 9.35 & 0.09 & 0.432 & 7.47 & 0.09 \\
$\mathbf{M g N O}_{3}$ & 0.574 & 16.91 & 0.14 & 0.529 & 10.32 & 0.15 & 0.484 & 8.61 & 0.08 \\
$\mathbf{N a B r}$ & 0.622 & 18.86 & 0.13 & 0.576 & 12.16 & 0.14 & 0.532 & 8.93 & 0.15 \\
$\mathbf{N a C l}$ & 0.757 & 18.98 & 0.24 & 0.753 & 18.11 & 0.18 & 0.747 & 15.30 & 0.08 \\
$\mathbf{K C l}$ & 0.868 & 42.59 & 0.15 & 0.843 & 27.01 & 0.23 & 0.823 & 21.74 & 0.21 \\
\hline
\end{tabular}

* Average of three repetitions, ** Average deviation of three repetitions

Figure 1 shows the isotherms of the test product. Isotherms are of type III according to the classification of Brunauer et al., 1940 [32].

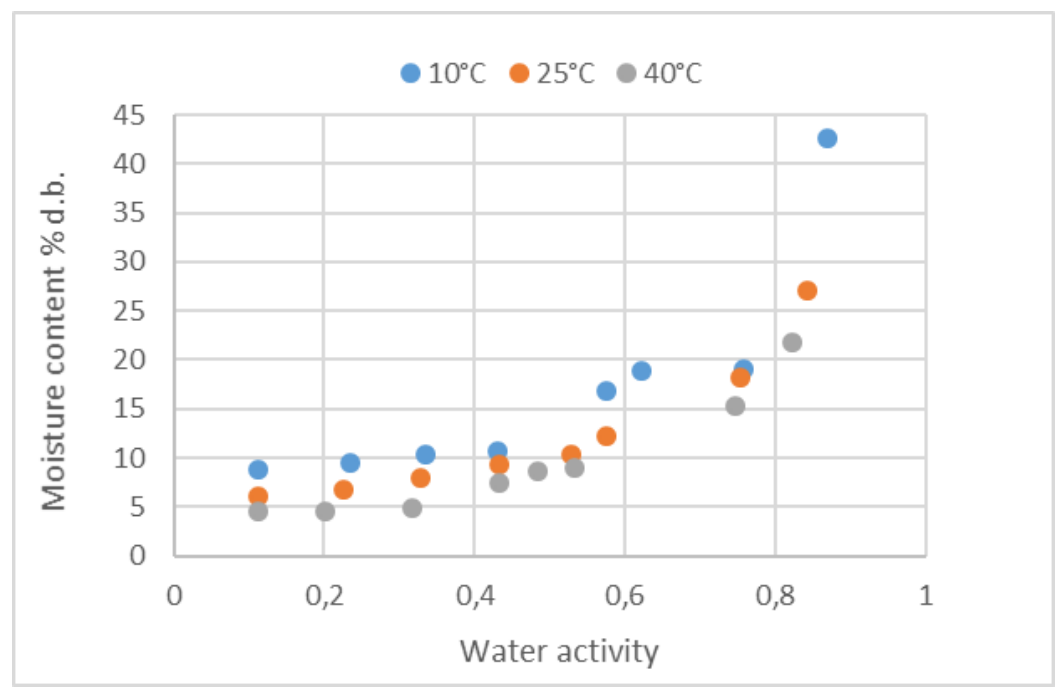

Figure 1. Desorption isotherms for $10^{\circ} \mathrm{C}, 25^{\circ} \mathrm{C}$ and $40^{\circ} \mathrm{C}$.

The resulting coefficients from the present study for three parametrical models (A, B, C) and the relevant values of average relative error $\mathrm{P}, \%$ and standard deviation SEM are presented in table 3 . The graphical analysis of the analyzed sample residues is presented on figure 2 .

Table 3. Coefficients of the models (A, B, C), average relative error $\mathrm{P}, \%$ and standard deviation SEM

\begin{tabular}{cccccc}
\hline Model & A & B & C & P & SEM \\
\hline Oswin & 15.519 & -0.172 & 0.540 & 15.59 & 2.49 \\
Halsey & $\mathbf{4 . 1 6 1 0}$ & $\mathbf{- 0 . 0 2 9}$ & $\mathbf{1 . 6 0 4}$ & $\mathbf{1 0 . 0 1}$ & $\mathbf{2 . 1 7}$ \\
Henderson & 0.00047 & 19.392 & 1.445 & 17.65 & 3.75 \\
Chung-Pfost & 162.309 & 0.1460 & 19.120 & 18.12 & 4.88 \\
\hline
\end{tabular}



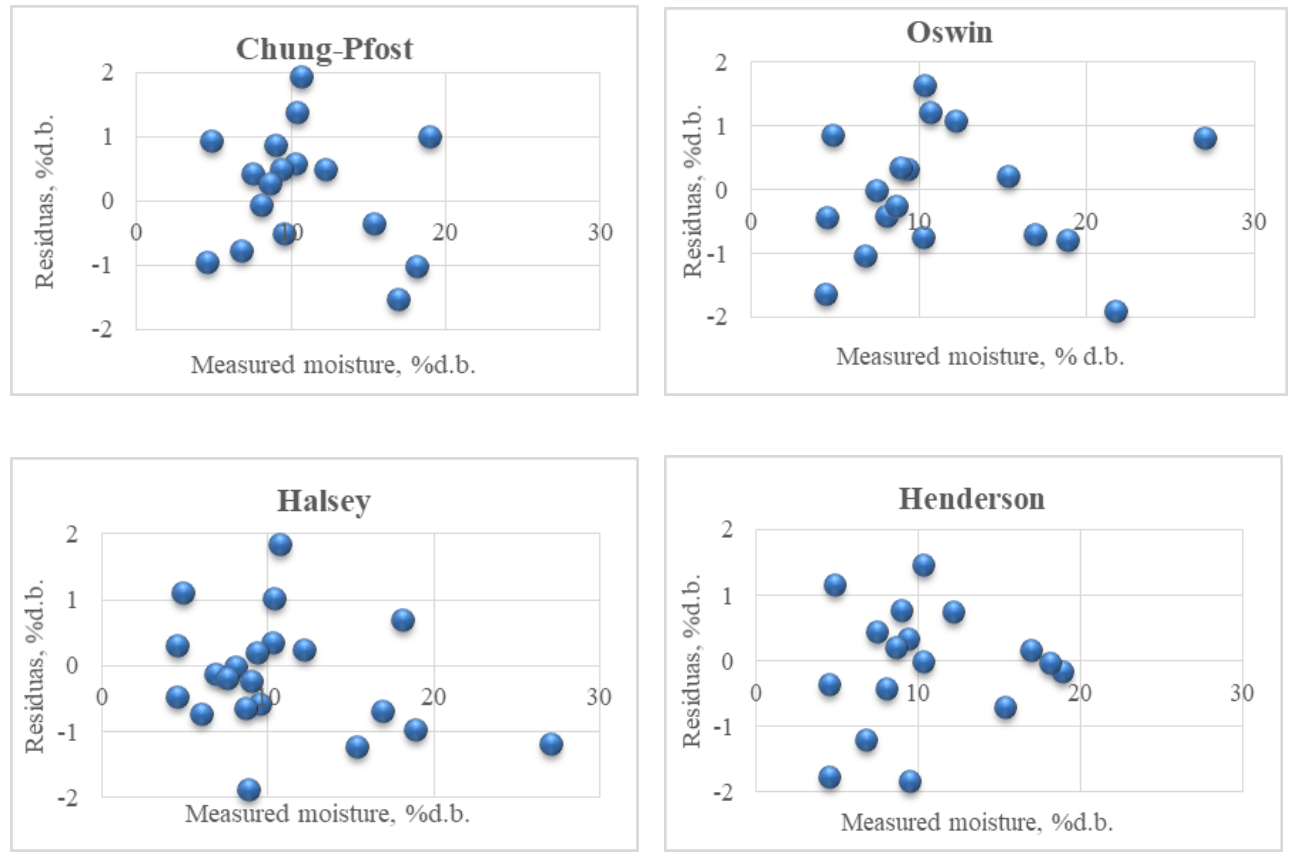

Figure 2. Residues graphical analysis.

The data in table 3 show that the lowest values of P and SEM are taken with the modified model of Halsey. The residues deviation is with random character by the modified model of Oswin from the graphical analysis. As a result, according to the criteria for estimation and usefulness of the models, we can recommend for description the desorption isotherms of a mixture for raw energy bars of fresh fruits of Zizyphus jujuba Mill of Bulgarian origin, as the most useful - the modified model of Halsey, and as a second - the modified model of Oswin.

For calculation the MMC the equation of Brunauer-Emmett-Teller is put in a linear type [8]. The linearization with trial data for $\mathrm{a}_{\mathrm{w}}<0.5$ is presented on figure 3 .

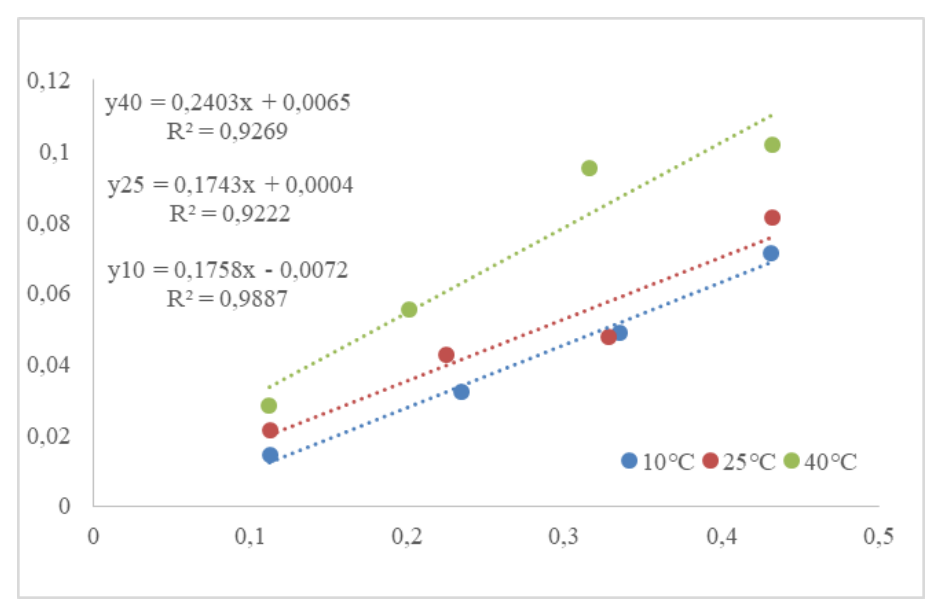

Figure 3. Linearization of the BET model 
The values of MMC are calculated from the received coefficients of the linear equations and are presented in table 4.

Table 4. Monolayer moisture content, $\%$ d.b.

\begin{tabular}{cc}
\hline $\mathbf{t}\left({ }^{\mathbf{0}} \mathbf{C}\right)$ & Desorption \\
\hline $\mathbf{1 0}$ & 5.46 \\
$\mathbf{2 5}$ & 5.72 \\
$\mathbf{4 0}$ & 4.05 \\
\hline
\end{tabular}

It is obvious from the data in the table that the temperature does not affect MMC. The highest value is calculated for temperature $25^{\circ} \mathrm{C}$, and the lowest for $40^{\circ} \mathrm{C}$. In relation to the received results we can assume that in moisture of raw energy bars' mixture in the range from to $4.05 \%$ d.m. to $5.72 \%$ d.m., the microorganisms' growth will be lowered to minimum for a more prolonged period of time [25]. It is confirmed in a surveyed article of Syamaladevi et al., 2016, that flour products' pathogenic microbiological safety is provided through considerable reduction of the product's moisture [33].

\section{Conclusions}

1. A data base of the physico-chemical composition of the ready mixture for raw energy bars is received, as the content of carbohydrates $-24.45 \%$ and nourishing fibre $-22.08 \%$, is most highly reported.

2. A database of desorption isotherms of for temperatures $10^{\circ} \mathrm{C}, 25^{\circ} \mathrm{C}$ and $40^{\circ} \mathrm{C}$ and aw in the range between $11 \%$ to $85 \%$.

3. The desorption isotherms of the finished mixture are of type III according to the classification of Brunauer et al.

4. It is established that the temperature affects the desorption capacity of the ready mixture for raw energy bars of fresh fruits of Zizyphus jujuba Mill.

5. The equilibrium humidity of the studied product decreases with increasing temperature at constant water activity.

6. Throughout the statistic treatment appropriate models responding to the commonly accepted criteria for description of sorption isotherms are recommended - most useful - the modified model of Halsey, and second - the modified model of Oswin. The models can be used for calculation of the equilibrium moisture for the conditions of the experiment.

7. MMC for the process of desorption are calculated with trial data for $\mathrm{a}_{\mathrm{w}}<0.5-$ $10^{\circ} \mathrm{C}-5.46 \%$ d.b., $25^{\circ} \mathrm{C}-5.72 \%$ d.b. and $40^{\circ} \mathrm{C}-4.05 \%$ d.b.

\section{Acknowledgements}

This study was part of the Fund Scientific Research "FS N11/20-H", director project: Assoc. Prof. PhD Albena Georgieva Durakova, University of Food Technologies - Plovdiv, Bulgaria.

\section{References}

1. R. Moreira, F. Chenlo, J. Sineiro, M. Sánchez, S. Arufe, J. Appl. Phycol. 28 (1), 609618, (2016).

2. Y. Suhag, G. A. Nayik, V. Nanda, J. Food Meas. Charact. 12 (4), 2553-2560, (2018). 
3. R. Kulchan, W. Boonsupthip, P. Suppakul, J. Food Eng. 100 (3), 461-467, (2010).

4. T. P. Labuza, B. Altunakar, Water activity prediction and moisture sorption isotherms. Water activity in foods: fundamentals and applications, 161-205, (2020).

5. M. Dupas-Langlet, J. Dupas, S. Samain, M.-I. Giardiello, V. Meunier, L. Forny, J. Food Eng., 184, 53-62, (2016).

6. S. Brunauer, P.H. Emmett, E. Teller, JACS, 60 (2), 309-319, (1938).

7. A. Nascimento, M. E. Cavalcanti-Mata, M. E. Martins Duarte, M. Pasquali, H. M. Lisboa, J. Food Process Eng., 42 (6), e13228, (2019).

8. M. Naderi, Surface Area: Brunauer-Emmett-Teller (BET). In Progress in filtration and separation (pp. 585-608). Academic Press, (2015).

9. A. Pereira, M. Maraschin, J. Ethnopharmacol., 160, 149-163, (2015).

10. J. Asgarpanah, E. Haghighat, J. Pharm. Pharmacol., 6 (31), 2332-2339, (2012).

11. A. M. Pawlowska, F. Camangi, A. Bader, A. Braca, Food Chem, 112 (4), 858-862, (2009).

12. J. Li, L. Shan, Y. Liu, L. Fan, L. Ai, Int. J. Biol. Macromol., 49 (3), 255-259, (2011).

13. S. M. Al-Reza, J. L. Yoon, H. J. Kim, J. S. Kim, S. C. Kang, Food Chem. Toxicol. 48 (2), 639-643, (2010).

14. A. Wojdyło, A. Carbonell-Barrachina, P. Legua, F. Hernández, Food Chem, 201, 307314, (2016).

15. B.S. Standard BDS 754:1980/Amendment 4: 2003

16. B.S. Standard, pH - BDS 11688: 1993

17. B.S. Standard, Dry matter - BDS EN ISO 12145:2000

18. B.S. Standard, TTA - BDS EN ISO 6996:1993

19. B.S. Standard, Fibre - BDS EN ISO 11374:1986

20. B.S. Standard, Fat content - BDS EN ISO 6997:1984

21. B.S. Standard, Carbohydrates - BDS EN ISO 7169:1989

22. B.S. Standard, Proteins, in Reglement (EO) №152/2009

23. B.S. Standard, Energy value - Regulation 1169:2011, Appendices IVX ; XV

24. AOAC, 960.39 (Washington, DC), 15 ed. AOAC. (1990)

25. L. Bell, T. Labuza, AACC, 33-36, (2000)

26. A. Durakova, A. Bogoeva, V. Yanakieva, T. Gogova, K. Choroleeva, E3S Web of Conferences, 180, 03007, EDP Sciences, (2020).

27. A G Durakova, A L Bogoeva, A P Krasteva and M L Temelkova, IOP Conf. Series: Materials Science and Engineering, (2020).

28. Albena Durakova, E3S Web of Conferences 180, 03008 (2020).

29. L. E. Rojo, C. M. Villano, G. Joseph, B. Schmidt, V. Shulaev, J. L. Shuman, I. Raskin, J Cosmet Dermatol., 9 (3), 185-195, (2010).

30. K. Muzaffar, P. Kumar, Powder Technol., 291, 322-327 (2016).

31. R. Muangrat, C. Nuankham, Food Sci. Nutr., 6(3), 585-593 (2018).

32. S. Brunauer, L. S. Deming, W. E. Diming, E. Troller, JACS, 62, 1723-1732, (1940)

33. R. M. Syamaladevi, J. Tang, R. Villa-Rojas, S. Sablani, B. Carter, \& G. Campbell, Comprehensive Reviews in Food Science and Food Safety, 15 (2), 353-370, (2016). 